\title{
Ege Üniversitesi Tıp Fakültesi Hastanesi'nde korona virüs aşısı olan kişilerin korona virüs aşısı hakkında bilgi düzeylerinin ve erişkin aşılaması durumlarının değerlendirilmesi
}

\author{
Evaluation of knowledge levels and other adult vaccines situations who vaccinated \\ for coronavirus vaccine in Ege University Faculty of Medicine Hospital \\ Dilşah Başkol ${ }^{1}$ Deniz Akyol ${ }^{1}$ Selin Ece Taşbakan ${ }^{2}$ (D) \\ Hüsnü Pullukçu ${ }^{1}$ Meltem Işıkgöz Taşbakan ${ }^{1}$ \\ ${ }^{1}$ Ege Üniversitesi Tıp Fakültesi, Enfeksiyon Hastalıkları ve Klinik Mikrobiyoloji, İzmir, Türkiye \\ ${ }^{2}$ İzmir Ekonomi Üniversitesi Tıp Fakültesi, İzmir, Türkiye
}

\section{ÖZ}

Amaç: Bu çalışmada, Korona virüs aşısı için başvuran gönülülerin Korona virüs aşısı hakkında bilgi düzeyleri ile aşıya olan güveni arttıran faktörlerin ve erişkin aşılaması durumlarının değerlendirilmesi amaçlanmıştır.

Gereç ve Yöntem: Bu çalışma, tanımlayıcı, kesitsel bir çalışmadır. Çalışmaya 1-31 Aralık 2020 tarihleri arasında Korona virüs aşısı için başvuran 18 yaş ve üzeri gönüllüler dahil edildi. Gönüllülere, sosyodemografik özellikleri, Influenza, Hepatit B ve pnömokok enfeksiyonlarına karşı aşılanma durumları ve Korona virüs aşısı hakkında bilgi edinme yolları ile bilgi düzeyleriyle ilgili sorulardan oluşan bir anket uygulandı. İstatistiksel analiz Ki kare testi ile yapıldı ve $p<0,05$ değeri anlamlı kabul edildi.

Bulgular: Çalışmaya katılan 232 gönüllünün 111'i $(\% 47,8)$ erkekti. Ortalama yaş 45,2 $\pm 10,3$ yıl (18$62)$ idi. Gönüllülerin \%72'si $(n=167)$ sağlık çalışanıydı ve \%90,5’i $(n=210)$ yüksek lisans derecesine sahipti. Sağlık çalışanları grubunda 54 katılımcı (\%32), sağlık çalışanı olmayan grupta 32 katılımcıda $(\% 13,8)$ en az bir kronik hastalık vardı $(p=0,007)$. Hepatit B'ye yönelik bağışıklanma açısından sağlık çalışanları ve sağlık çalışanı olmayanlar arasında istatistiksel olarak önemli fark vardı $(p<0,001)$. Bilgi edinmenin en sık başvurulan iki yolu akademik yayınları takip etmek $(\% 50, n=116)$ ve Sağlık Bakanlığı'nın açıklamaları (\%45,3, n=105) idi. Aşılamada güveni artıran iki değişken akademik yayın takibi $(O R=6,21)$ ve pnömokok aşısı yaptırmaktı $(p=0,049)$. Bir önceki sezon katııımcıların İnfluenza aşısı olma oranı \%21,2 iken COVID-19 pandemisi döneminde İnfluenza aşısı için istekli olan ve yaptırmış olanların oranı \%45,3 saptanmıştır.

Sonuç: COVID-19 enfeksiyonu ve diğer erişkin dönem aşılaması ile ilgili durumlarının belirlenmesi aşı uygulamalarının ve etkinliğinin sürdürülebilmesi açısından önemlidir. Mevcut pandemi ile İnfluenza başta olmak üzere diğer erişkin aşılarına yönelik de gönüllülük oranlarının artığı görülmektedir.

Anahtar Sözcükler: Erişkin aşılama, COVID-19, korona virüs aşısı.

***Bu çalışma, 9. Türkiye EKMUD Platformunda (20-23 Mayıs 2021) sözlü sunum olarak sunulmuştur.

\section{ABSTRACT}

Aim: In this study, it was aimed to evaluate knowledge levels with confidence in vaccine and other adult vaccines situations of volunteers who applied for coronavirus vaccine.

\footnotetext{
Sorumlu yazar: Deniz Akyol

Ege Üniversitesi Tıp Fakültesi, Enfeksiyon Hastalıkları ve Klinik

Mikrobiyoloji, İzmir, Türkiye

E-posta: denizakyol416@gmail.com

Başvuru tarihi: 23.03.2021 Kabul tarihi: 22.11.2021
} 
Materials and Methods: This study is a descriptive cross-sectional study. Volunteers aged 18 years and older who were admitted to our setting between 1 and 31 December 2020 were enrolled in the study. Volunteers were applied a questionnaire comprised of questions regarding their sociodemographic profile, their vaccination status against Influenza, Hepatitis $B$ and Streptococcus pneumoniae infections and way to get information and their knowledge about coronavirus vaccine. Statistical analysis was performed via Chi square test and a $p$ value $<0.05$ was considered significant.

Results: Of the 232 volunteers participated in the study, 111 (47.8\%) were male. The mean age was $45.2 \pm 10.3$ years (18-62). There were $72 \%(n=167)$ of the volunteers were healthcare workers and those who had master's degree were $90.5 \%(n=210)$. In healthcare workers group 54 patients $(32 \%)$, in non-healthcare workers group 32 patients (13.8\%) had at least one chronic disease $(p=0.007)$. There was statistically significant difference in vaccinated patients among healthcare workers and nonhealthcare workers for hepatitis $B(p=0.000)$. The most common two ways to get information were following academic publications (50\%, $n=116)$ and statements by the Ministry of Health $(45.3 \%$, $n=105)$. Two variables that increase confidence in vaccination were following academic publication $(O R=6.21)$ and getting a pneumococcal vaccine $(p=0.049)$. The rate of Influenza vaccination of the participants in the previous season was $21.2 \%$, and the rate of those who were willing and had the Influenza vaccination during the COVID-19 pandemic period was $45.3 \%$.

Conclusion: Determining the factors affecting the level of knowledge about COVID-19 infection and other adult vaccination is important in terms of maintaining the vaccine applications and effectiveness. With the current pandemic, it is seen that volunteering rates for other adult vaccines, especially influenza, have increased.

Keywords: Adult vaccination, COVID-19, coronavirus vaccine.

${ }^{* * *}$ This study was presented as an oral presentation on the 9th EKMUD Platform (20-23 May 2021).

\section{GíRiş}

Aşı ile bağışıklama, hayatı tehdit eden hastalıkların kontrol altına alınmasında ve eradike edilmesinde çevre sağlığı ve temiz su hizmetlerinden sonra en etkili, güvenli ve maliyet etkin sağlık hizmetidir. Aşı ile önlenebilir enfeksiyon hastalıklarının çoğunun sıklığında aşılama programları sonucu \%99 oranında azalma sağlanmıştır (1). Aşılama sadece çocukluk dönemini değil, bütün yaş gruplarını yaşam boyu kapsamalıdır ancak erişkin dönemde aşılanma oranları çocukluk dönemine göre düşüktür (2). Çocukluk döneminde başlayan bağışıklama programlarının kesintiye uğramadan erişkin ve yaşlılık döneminde de devam ettirilmesi yani yaşam boyu bağışıklama, sağııkı bir toplum için gereklidir.

Altta yatan risk faktörlerinden bağımsız olarak tüm erişkinlere difteri-tetanos ve Influenza aşısı önerilmektedir. Hepatit B aşısı da 1998 yılından itibaren çocuklarda rutin, erişkinlerde riskli grup aşı şeması içinde bulunmaktadır (2). Pnömokok aşısı biri polisakkarit (PPSV23) diğeri konjuge (PCV13) olmak üzere iki tip olup risk gruplarında önerilmektedir (2). Son yıllarda aşı ile bağışıklamaya karşı farklı olumsuz tutum ve davranışlar ile karşılaşıımaktadır (3). Aşılamaya yönelik tereddütler, aşı ile önlenebilir hastalıkların sıklığının ve salgın hastalık riskinin artmasına neden olmaktadır. Ancak 2020 yılında tüm dünyayı etkisi altına alan COVID-19 pandemisi sırasında aşılara olan ilgi artmıştır. Bu doğrultuda aşı karşıtlığının azalması tüm dünyada beklenmektedir.

Küresel salgın olarak kabul edilen ve milyonlarca insanı enfekte eden SARS-CoV-2'ye karşı verilen mücadelede etkili ve güvenilir aşı geliştirilmesi önemli bir basamaktır ve birçok aşı çalışması da halen devam etmektedir.

Ülkemizde 18 Aralık 2020'de Coronavac aşısı acil kullanım onayı almış ve 15 Ocak 2021 tarihinde uygulanmaya başlamıştır. Bu tarihten önce Sağlık Bakanlığı öncülüğünde Ege Üniversitesi Hastanesi Enfeksiyon Hastalıkları ve Klinik Mikrobiyoloji Anabilim Dalı'nın da içinde bulunduğu 14 merkezde sağlıklı gönüllülere Coronavac aşısının Faz 3 çalışması yapılmıştır.

SARS-CoV-2'nin neden olduğu COVID-19 enfeksiyonu, Mayıs 2021 ilk hafta sonu itibariyle, 154 milyon bildirilmiş vaka ve 3,2 milyon bildirilen ölüm ile dünya çapında ciddi bir salgın haline gelmiştir (4). COVID-19 pandemisinin seyrini önemli boyutta değiştirmesi beklenen en önemli yaklaşımlardan birisi de aşılamadır. Coronovac aşısı Çin kökenli bir üretici tarafından üretilen inaktive virüs aşısıdır, Brezilya, Türkiye, Endonezya, Çin ve Şili'de Faz 3 çalışmaları yapılmıştır. Türkiye'deki Faz 3 çalışması 12 ildeki 24 merkezde çift kör, plasebo kontrollü olarak gerçekleştirilmiş olup gönüllüler içinde ilk aşamada sadece sağlık personeline 1:1 randomizasyonla yapılan çalışma $20 \mathrm{Kasım}$ 
tarihinden itibaren tüm gönüllülere açılmıştır (5). Çalışmamızda tüm gönüllülere uygulanmasının başladığı zaman dilimi seçilerek 1-31 Aralık 2020 aralığında yapılmıştır.

$\mathrm{Bu}$ çalışmada, Korona virüs aşısı için başvuran gönüllülerin Korona virüs aşısı hakkında bilgi düzeyleri ile aşıya olan güveni arttıran faktörlerin ve erişkin aşılaması durumlarının değerlendirilmesi amaçlanmıştır.

\section{GEREÇ ve YÖNTEM}

Ege Üniversitesi Tıp Fakültesi Hastanesi, 4.300.000'den fazla nüfusu olan İzmir'deki 2400 yataklı bir hastane olup bölgedeki en büyük hastane olma özelliğine sahiptir. Enfeksiyon Hastalıkları ve Klinik Mikrobiyoloji Anabilim Dalı'na 1-31 Aralık 2020 tarihleri arasında Korona virüs aşısı olmak için Faz-3 çalışmasına dahil olmak üzere başvuran bireyler araştırma grubu olarak tanımlandı. Araştırma grubu, sağlık çalışanı olan ve olmayanlar olarak ikiye ayrıldı. Dahil edilme kriterleri; Anabilim Dalı'mıza Korona virüs aşısı olmak için başvurmak, hasta bilgilendirme ve onam formu imzalanmak ve 18 yaş ve üstü olmak olarak belirlendi.

Çalışma aracı olarak gönüllü tarafından doldurulacak Korona virüs aşısına olan güveni bir en düşük, 10 en yüksek olmak üzere puanlanan bir anket kullanıldı. Ankette; demografik bilgiler (yaş, cinsiyet, meslek, eğitim düzeyi), sağlık çalışanı olup olmamak, tıbbi özgeçmiş, hepatit B, Influenza ve pnömokoka karşı aşılanma durumları sorgulandı. Korona virüs aşısına karşı bilgi düzeyi ile aşıya yönelik tutum belirten beşinde evet/hayır şeklinde ikili yanıt sistemi kullanılan toplam 12 soru hazırlandı.

Çalışmamız Helsinki Deklarasyonu kararlarına, hasta hakları yönetmeliğine uygun olarak planlandı ve Ege Üniversitesi Tıp Fakültesi klinik araştırmaları etik kurulundan 29.1.2021 tarih ve E.327847 sayılı etik kurul onayı alındı.

Verilerin değerlendirilmesi için SPSS istatistiksel analiz programı kullanıldı. Bağımsız değişkenlerin bağımlı değişken üzerindeki ilişkisi ki-kare testi ile araştırılmıştır. Anlamlı bulunan bağımsız değişkenlerin bağımlı değişken üzerindeki ilişki tek değişkenli analiz ile değerlendirildi. İki değişkenin anlamlı bulunması nedeniyle lojistik regresyon yapılamadı. İstatistiksel olarak $p<0,05$ anlamlı kabul edildi.

\section{BULGULAR}

Enfeksiyon Hastalıkları ve Klinik Mikrobiyoloji Anabilim Dalı'na Koronavirüs aşısı olmak için 131 Aralık 2020 tarihleri arasında başvuran 370 kişiden çalışmaya dahil edilme kriterlerini sağlayan 232 kişi katıldı. Gönüllülerin \%52,2'si $(n=121)$ kadın, \%47,8'i ( $n=111)$ erkek, yaş aralığı 18-62 (ortalama yaş 45,2 $\pm 10,3$ ) idi. \%72'si $(n=167)$ sağlık çalışanı olup lisans ya da yüksek lisans eğitimi almış olanların oranı \%90,5 $(n=210)$ saptandı. Yirmi yedi $(\% 11,6)$ kişide hipertansiyon olmak üzere $63 \quad(\% 27,2)$ gönüllü de kronik hastalık vardı. Sağlık çalışanı olanların \%32'si $(n=54)$, olmayanların da \%13,8'i en az bir kronik hastalığa sahipti $(p=0.007)$.

Pnömokok aşısı olduğu belirtenlerin oranı $\% 15,9$ 'du $(n=37)$. Sağlık çalışanı olan ve olmayanların pnömokoka yönelik aşılanma öyküsünün benzer olduğu saptandı (\%16,3$\% 16,1 \mathrm{p}=1.000$ ). Hepatit B'ye yönelik aşılanma öyküsünün sağlık çalışanlarında daha fazla olduğu görüldü (\%81,3-\%46,9 p=0.000) (Tablo1).

Gönüllülerin yalnızca \%21,2'si (n=49) 2019-2020 sezonunda Influenza aşısı olmuştu. Influenza aşısı öyküsü sağlık çalışanı olan ve olmayanlarda benzer saptandı ( $p=0.125)$ (Tablo 1). Gönüllülerin $\% 8,2$ 'si $(n=19)$ 2020-2021 sezonunda mevsimsel Influenza aşısını olduğunu, $\% 37,1^{\prime} i(n=86)$ ise aşı olmaya istekli olduğunu belirtti. Sağlık çalışanı alt grubunda ise bu oranlar sırasıyla \%0,9 $(n=15)$, $\% 41,3(n=69)$ olarak saptandı $(p=0.047)$.

Korona virüs aşısı hakkında bilgi edinme kaynakları sorgulandığında en sık akademik yayın takibi (\%50, $\mathrm{n}=116)$ ve sağlık bakanlığı açıklamaları bulundu (\%45,3, $n=105)$. Sağlık çalışanlarının \%62,9'u $(n=105, \quad p=0,000)$ akademik yayın takibi ile \%40,1'i $(n=67)$ Sağlık bakanlığı açıklamaları ile korona virüs aşısı hakkında bilgi edindiğini belirtti $(p=0,012)$. Uluslararası basın/medya takibi ile bilgi edinilme sağlık çalışanlarında daha fazlaydı (\%29,3; $\% 10,8 \mathrm{p}=0,005)$ (Tablo-2).

Gönüllülerden korona virüs aşısına olan güveni 1 en düşük, 10 en yüksek olmak üzere puanlaması istendiğinde \%28,4'ünün $(n=66) 8$ puan, $\% 1,7$ 'sinin 3 ve daha düşük puan verdiği saptandı (ortalama $8 \pm 2$ ). Sağlık çalışanı olan ve olmayanlarda korona virüs aşısına olan güven benzer saptandı $(p=0.630)$.

Aşılamada güveni artıran değişkenler için pnömokok/hepatit B ve Influenza aşılarını yaptırmak ile akademik yayın takibi/Sağılı Bakanlığı açıklamaları/ uluslararası basın/medya takibi analiz edildi. Akademik yayın takibi $(p=0,003$, olasılıklar oranı $=6,21, \% 95$ GA 1,7$21,9)$ ve pnömokok aşısı yaptırmak istatistiksel olarak anlamlı saptandı $(p=0,049)$. Pnömokok aşısı yaptıran 37 kişinin tamamının güven 
skorunun beş ve üzerine olması nedeniyle olasılıklar oranı hesaplanamadı.

Birinci derece yakını ağır COVID-19 hastalığı geçirdiğini \%11,2 $(n=26)$, arkadaşı ağır COVID19 hastalığı geçirdiği \%34,5 (n=80), daha önce COVID-19 enfeksiyonu dışı pnömoni nedeniyle hastanede yatış öyküsü olduğunu \%4,7 $(n=11)$ ve COVID-19 enfeksiyonu nedeniyle hayatını kaybeden yakını/tanıdığı olduğunu \%37,5 $(n=87)$ gönüllü belirtti. COVID-19 enfeksiyonu nedeniyle hayatını kaybeden yakını/tanıdığı olması, sağlık çalışanı olan gönüllülerde istatistiksel olarak anlamlı olarak daha fazla saptandı (\%43,7; $\% 21,5 p=0.003)$.

Tablo-1 Korona virüs aşı gönüllülerinde Pnömokok, Hepatit B ve İnfluenza'ya karşı aşılama öyküleri.

\begin{tabular}{cccc}
\hline & Sağlık çalışanı olanlar & Sağlık çalışanı olmayanlar & $\mathbf{p}$ \\
\hline Pnömokok & $\% 16,3$ & $\% 16,1$ & 1,0 \\
Hepatit B & $\% 81,3$ & $\% 46,9$ & $<0,001$ \\
Influenza & $\% 24,1$ & $\% 13,8$ & 0,125 \\
\hline
\end{tabular}

Tablo-2. Korona virüs aşısı hakkında bilgi edinme kaynakları.

\begin{tabular}{lccc}
\hline & Tüm gönüllüler & Sağlık çalışanları & $\mathbf{p}$ \\
\hline Akademik yayın takibi & $\% 50$ & $\% 62,9$ & $<0,001$ \\
Sağlık bakanlığı açıklamaları & $\% 45,3$ & $\% 40,1$ & 0,012 \\
Uluslararası basın/medya takibi & $\% 10,8$ & $\% 29,3$ & 0,005 \\
\hline
\end{tabular}

\section{TARTIŞMA}

COVID-19 enfeksiyonu ve diğer erişkin dönem aşılaması ile ilgili durumlarının belirlenmesi çalışmamızın çoğunluğunu oluşturan başta sağlık çalışanları olmak üzere aşı uygulamalarının ve etkinliğinin sürdürülebilmesi açısından önemlidir

Çalışmamıza katılan gönüllülerin \%72'si sağlık çalışanlarından oluşmaktaydı. Bunun nedeni olarak Faz-3 aşılaması için gönüllü alımında öncelikle hastane içi duyuruların etkisi olduğu düşünüldü. Ayrıca sağlık çalışanı olan grupta kronik hastalığa sahip olma oranının da olmayanlarda göre istatiksel olarak yüksek bulunmasının nedeni de COVID-19 hastalığının seyrinin kronik hastalığı olan bireylerde daha ağır olduğunun bilinmesi ve bu kişileri aşılamaya yönlendirmesi şeklinde değerlendirildi.

Pnömokok aşısı özellikle riskli gruplarda (65 yaş üstü, diyabetes mellitus, kronik akciğer hastalığı, kronik kronik kalp hastalığı, kronik karaciğer hastalığı gibi) aşılama ülkemizde önerilmektedir. PPSV23 aşısının \%50-85, PCV13 aşısının \%75 oranında invaziv pnömokok enfeksiyonlarına karşı koruduğu bildirilmiştir (6). COVID-19 hastalığı için de benzer özellikli risk gruplarına sahip olan pnömokok için aşılanma öyküsü; sağlık çalışanı olan ve olmayan grupta benzer saptandı. Bunun nedeni, sağlık hizmeti çalışanı olmanın ek kronik hastalığa sahip olmadıkça pnömokokkal hastalık için risk grubuna dahil olmaması olabilir.

Hepatit B enfeksiyonu sık görülen ve akut enfeksiyonları sırasında organ hatta hayat kaybı ile sonuçlanabilen; kronik enfeksiyonuna bağlı siroz ve hepatosellüler kanser (HCC) gibi komplikasyonları da ortaya çıkabilen ve aşılama ile önlenebilen bir hastalıktır. Aşının koruyuculuğu \%90-95 olarak bildirilmektedir (7). Çalışmamızda hepatit B aşılanma öyküsü sağlık çalışanlarında daha fazla saptandı. Bunun nedeni olarak mesleki nedenle risk grubunda olunması ve Çalışan Sağlığı ve Güvenliği Birimi tarafından da bu aşılanmanın denetlenmesinin olabileceği düşünüldü.

Çalışmamızda 2019-2020 sezonunda Influenza aşısı olanların oranı \%21,2'si $(n=49)$ iken 20202021 sezonu için Influenza aşısı için istekli olan ve aşıyı hali hazırda yaptırmış olanların oranı toplam \%45,3 ( $n=105)$ saptandı. 2009 yılı H1N1 pandemisinde Ege Üniversitesi'nde 807 sağlık çalışanın dahil edildiği bir çalışmada, bir önceki sene aşılanma oranı \%19 iken pandemi döneminde $\% 30,4$ olarak tespit edilmiştir (8).

Pham Le Am ve arkadaşlarının yaptığı bir araştırmada hekimlerin COVID-19 farkındalık düzeyi üzerinde etkili olan bilgilerini sosyal medya $(\% 91,1)$, Sağlık Bakanlığı $(\% 82,6)$ ve 
televizyon $(\% 79,2)$ gibi çeşitli medya aracılığıyla topladıklarını ve bu oranın hekimler arasında yüksek olduğu görülmüştür (9). Bhagavathula ve arkadaşlarının yaptığı başka bir çalışmada da katılımcıların çoğu (\%61) COVID-19 hakkındaki bilgilerini sosyal medyadan ve resmi kamu sitelerinden edindiğini belirtmiştir (10). Bizim çalışmamızda bilgiye ulaşma yolu olarak diğer çalışmalardan farklı olarak sosyal medya yerine akademik yayın takibi bulunmuştur.

Türkiye'de yaklaşık üç kişiden birinin (\%31) COVID-19 aşısı konusunda kararsız olduğunu bildirilmiştir (11). Evrimsel psikiyatrist Randolph Nesse'nin de belirttiği gibi duygularımız ölümden kaçınmamıza yardımcı olan uyarıcıdırlar (12). Çalışmamızda da COVID-19 enfeksiyonu nedeniyle hayatını kaybeden yakını/tanıdığı olunmasının da aşı olmaya teşvik edebilecek bir faktör olabileceği düşünülmektedir. Bunun yanı sıra hayatını kaybeden yakını/tanıdığı olmasa da aşıyı gönüllü olarak yaptırmak isteyen bir grup da vardır.

Aşı ve aşı karşıtlığına yönelik 2018 yılında yapılan 284 hekimin dahil edildiği bir çalışmada katılımcıların \%81,3'ü aşıların sağlık için gerekli olduğunu düşünürken $\% 27,1^{\prime} i$ aşıların içeriği ile ilgili çeşitli endişelere sahip olduğunu belirtmiştir. Aynı çalışmada hekimlerin \%6,7'si Influenza, $\% 0,7$ 'si de pnömokok aşısını gereksiz bulduklarını düşündüklerini ifade etmiştir (13). Paguio ve arkadaşlarının yaptığı bir çalışmada (14), 2020 yılının Şubat ve Mart aylarında, çevrimiçi arama motoru üzerinden rutin önerilen aşılarla ilgili yapılan aramaların hacimleri incelenmiş; pnömokok ve grip aşılarına dünya çapında artan ilgiye işaret eden pozitif bir korelasyon görülmüş. Aynı çalışmada pandemiden önceki beş yıl için de aynı aylardaki arama hacimlerine bakılarak bunun mevsimsel bir trend olmadığı, COVID-19 kaynaklı olduğu yönünde değerlendirilmiştir (14). Çalışmamızda da bir önceki sezon katılımcıların \%21,2'si İnfluenza aşısı olmuşken, COVID-19 enfeksiyonu sonrası aşı için istekli olan ve yaptırmış olanların oranı \%45,3'e yükselmiştir. Mevcut pandemi bir yandan Koronavirus aşılaması için endişeleri beraberinde getirirken diğer erişkin aşılara yönelik de gönüllülük oranlarının arttığı görülmektedir.

Çalışmanın kısıtılıklarını, kesitsel bir çalışma olması, araştırmanın aşılama için başvuran gönüllüler ile sınırlı olması, katılımcıların büyük çoğunluğunun sağlık çalışanı olması ve yüksek lisans derecesine sahip olması, Hepatit B ve pnömokok için aşılamaya yönelik antikor bakılmamış olması ve bağışıklama bilgi düzeyi ile bağışıklama hizmetlerine karşı tutumun değerlendirilmesinde standart bir ölçeğin olmaması oluşturmaktadır.

\section{SONUÇ}

COVID-19 enfeksiyonu ve diğer erişkin dönem aşılaması ile ilgili bilgi düzeyini etkileyen ilişkili faktörlerin belirlenmesi aşı uygulamalarının ve etkinliğinin sürdürülebilmesi açısından önemlidir. Özellikle Sağlık Bakanlığı tarafından yapılan açıklamalar bu konuda önemli bir yere sahiptir. Ayrıca mevcut pandemi ile diğer erişkin dönem aşılarına yönelik de gönüllülük oranlarının arttığı görülmektedir.

Çıkar çatışması: Çıkar çatışması beyanı bulunmamaktadır.

\section{Kaynaklar}

1. Pickering LK, Baker CJ, Freed GL, et al. CID 2009; 49: 817-40.

2. EKMUD Erişkin Bağışıklama Rehberi. İstanbul: Arvin Yayınevi; 2016.

3. Dubé E, Laberge C, Guay M, Bramadat P, Roy R, Bettinger JA. Vaccine hesitancy. Hum Vaccin Immunother 2013 Aug; 9 (8): 1763-73.

4. WHO. Coronavirus disease (COVID-19) Situation Report 177. 2020. Available from: https://covid19.who.int/

5. İskit Topeli A, Tanrı̈ver Durusu M, Uzun Ö. COVID-19 Pandemi Raporu (20 Mart-20 Kasım 2020). Ankara: Hacettepe İç Hastalıkları Derneği Yayınları; Ocak 2021.

6. Vadlamudi NK, Parhar K, Altre Malana KL, Kang A, Marra F. Immunogenicity and safety of the 13-valent pneumococcal conjugate vaccine compared to 23-valent pneumococcal polysaccharide in immunocompetent adults: A systematic review and meta-analysis. Vaccine 2019 Feb 14; 37 (8): 1021-29.

7. European Association For The Study Of The Liver. EASL clinical practice guidelines: Management of chronic hepatitis B virus infection. J Hepatol 2012 Jul; 57 (1): 167-85. 
8. Arda B, Durusoy R, Yamazhan T, et al. Did the pandemic have an impact on influenza vaccination attitude? A survey among health care workers. BMC Infect Dis 2011; 11: 87

9. Giao H, Le An P, Thi Ngoc Han N, Van Khanh T, Kim Ngan V, Van Tam V. Knowledge and attitude toward COVID-19 among healthcare workers at District 2 Hospital, Ho Chi Minh City. Asian Pac J Trop Med 2020; 13 (March):6-11.

10.Bhagavathula AS, Aldhaleei WA, Rahmani J, Mahabadi MA, Bandari DK. Novel Coronavirus (COVID19) Knowledge and Perceptions: A Survey of Healthcare Workers. medRxiv https://doi.org/10.1101/2020.03.09.20033381

11.Salali GD,Uysal MS. Covid-19 vaccine hesitancy is associated with beliefs on the origin of the novel Coronavirus in the UK and Turkey. Psychol Med 2020 Oct 19;1-3.

12.Nesse RM. Good reasons for bad feelings: Insights from the frontier of evolutionary psychiatry. Penguin yayınevi 2019.

13.Akar SY, Öztürk GZ. Hekimlerin Aşı ve Aşı Karşıtlığı Hakkında Bilgi, Tutum ve Davranışlarının Değerlendirilmesi. FLORA 2020; 25 (4): 516-526.

14.Paguio JA, Yao JS, Dee CE. Silver lining of COVID-19: Heightened global interest in pneumococcal and influenza vaccines, an infodemiology study. Vaccine 2020 Jul 22; 38 (34): 5430-5435. 